\title{
Is Knowledge of Circular Economy, Pro-Environmental Behavior, Satisfaction with Life, and Beliefs a Predictor of Connectedness to Nature in Rural Children and Adolescents? A Pilot Study
}

\author{
Natalia Solano-Pinto ${ }^{1}\left(\mathbb{D}\right.$, Dunia Garrido $^{2}{ }^{(0)}$, Felipe Gértrudix-Barrio ${ }^{3} \mathbb{C}$ and \\ Raquel Fernández-Cézar ${ }^{4, *(D)}$ \\ 1 Psychology Department, Faculty of Education of Toledo, Castilla La Mancha University, 50, 13001 Ciudad \\ Real, Spain; natalia.solano@uclm.es \\ 2 Psychology Department, Faculty of Health Sciences of Talavera, Castilla La Mancha University, 50, \\ 13001 Ciudad Real, Spain; dunia.garrido@uclm.es \\ 3 Didactic of Musical, Plastic, and Body Expression Department, Faculty of Education of Toledo, Castilla La \\ Mancha University, 50, 13001 Ciudad Real, Spain; felipe.gertrudix@uclm.es \\ 4 Mathematics Department, Faculty of Education of Toledo, Castilla La Mancha University, 50, \\ 13001 Ciudad Real, Spain \\ * Correspondence: raquel.fcezar@uclm.es; Tel.: +34-925-268-800 (ext. 4743)
}

Received: 28 September 2020; Accepted: 26 November 2020; Published: 28 November 2020

\begin{abstract}
Sustainable development (SD) is crucial to maintaining and preserving the planet we live on. The new paradigm of circular economy (CE) corresponds to the sustainable development goals and includes environmental, economic, and social dimensions. The United Nations has set quality education and the search for good health and well-being in the long term as tools for achieving SD. This study aims to identify the predictors of connectedness to nature in children and adolescents using knowledge of $\mathrm{CE}$, pro-environmental behavior, beliefs about caring for the environment, and satisfaction with life as possible predictive variables. The exploration of the influence of these predictors on connectedness to nature, taking sex and age as covariates, was performed using a binary logistic regression model. We found that low scores on pro-environmental behavior, satisfaction with life, knowledge of waste management and $\mathrm{CE}$, and beliefs about environmental behavior were related to a low degree of connectedness to nature. Thus, our findings suggest that the educational system must promote not only the assimilation of knowledge and beliefs but also satisfaction with life given its relationship with connectedness to nature.
\end{abstract}

Keywords: pro-environmental behavior; connectedness to nature; knowledge; life satisfaction; circular economy; rural students; elementary education

\section{Introduction}

Sustainable development (SD) is crucial to maintaining and preserving the planet we live on. Responsibility for achieving this goal is shared among stakeholders, companies, and citizens. However, the definition of SD has varied since the concept's introduction in 1972, with the United Nations Conference on the environment in Stockholm, when international and national authorities first realized the influence of and linked issues that, up to that moment, ran along different avenues: the environment and economic development [1]. Later, and partly influenced by this, other significant studies came about, such as the Brutland report, which defined a concept of Sustainable Development that addresses the overall regeneration of ecosystems for the purpose of intergenerational equity [1]. This concept has 
evolved to the notion of circular economy (CE) in the last few years [2,3]. These authors agree that the three main pillars of sustainable development-environmental, economic, and social-are combined in the circular economy paradigm [4,5]. Nonetheless, Kirchehherr et al. [6], in a literature review, emphasize that the term "circular economy" is frequently depicted as "reduce, reuse, recycle" and it is rarely highlighted that $\mathrm{CE}$ necessitates a systemic shift. Moreover, they conclude that $\mathrm{CE}$ is primarily related to economic growth and only secondarily related to social development and caring for the environment. In this paper, we assume that the Circular Economy involves economic growth through the fostering of SD. It is an interdisciplinary approach that combines environmental and social sciences. It is a popular approach that helps policy-makers, governments, and scientists discuss the transition from a linear economy to a circular economy that globally contributes to SD, which now is not only perceived as economic, but as a necessity for human development in relation to the environment and as part of a society, or, furthermore, as living beings on Earth among many other living beings without hierarchies.

Since the notion of a circular economy involves sustainable development goals [7], it includes environmental, economic, and social dimensions. The SD goals, set by the UN 2030 Agenda for SD [8], include quality education and the search for good health and well-being in the long term as tools for achieving SD. Education plays a part in a citizen's life from an early age to university. In a broad sense, education, good health, and well-being are intertwined in the circular economy, which deals with information about and knowledge of the environment, the economy, and society and how to use resources, waste, energy, and goods to optimize the quality of life of living beings and the planet. Thus, it includes pro-environmental behaviors (PEBs), which are considered to be those behaviors that intentionally or unintentionally produce a positive effect on the environment (e.g., recycling) or produce as little damage as possible (e.g., the use of public versus private transportation) [9]. In this vein, authors have established two categories of PEBs. The first category is related to the question of whether collective public transportation, walking, or cycling is involved [10], while the second category includes behaviors that improve the quality of the environment, such as planting crops and cleaning fields or beaches [11]. Other authors include alternative types of behavior such as consumption or household saving behavior in relation to supplies [12]. In any case, it would seem from our literature review that PEB is a multidimensional construct that includes several types of behaviors that both foster sustainable development and improve health [13] by increasing the quality of life [14] and satisfaction with life [15]. In addition, some authors [16] report a bidirectional relationship between satisfaction with life and pro-environmental behavior. Nonetheless, although pro-environmental behavior seems to be influenced by psychological and socio-demographical factors, the ones that specifically influence this behavior have yet to be identified [17].

Although knowledge of the environment is prioritized over the social pillar of $\mathrm{CE}$ in some countries [5], in the context of CE they both should be balanced. Education does not involve only content or information, but also awareness [18], sensitization and citizenship activation, and pro-environmental behavior [19]. Moreover, it is worthwhile encouraging future generations to become proactive, and, so, working with children. Although education can promote pro-environmental behaviors [20], knowledge by itself is insufficient to achieve a change in citizens' behaviors respecting the environment, society, and themselves. Guo and Zhang [21] consider awareness to be as important as knowledge in determining the level of internalization and sensitization of CE in children. Since the last quarter of the 20th century, international and national agencies have considered education to be an important means by which to foster SD and create active citizens among students and future generations, and national and regional governments have included the aim of sustainable development in curricula for elementary and secondary education, as is the case in Spain [22].

Currently, much of the research on SD is focused on understanding and explaining behaviors that promote sustainable development. It highlights the concept of connectedness to nature, which means "the emotional affinity one feels with nature". It implies incorporating an emotional component in one's relationship with the environment $[23,24]$ that also addresses social identity [25]. In this 
sense, connectedness to nature makes a human being feel part of the planet, where it is considered to be important for life itself, both in relation to the human being and to all forms of life [26]. From this perspective, investigations have found positive relations between connectedness to nature and pro-environmental behaviors and intentions [27], specifically with regard to recycling, domestic saving and consumption behaviors [12], and participation in reforestation [28].

Other authors have found relationships between connectedness to nature and psychological health in adults in terms of a feeling of connectedness to nature and psychological restoration, particularly in rural and coastal settings compared with urban settings [29]. Along the same lines, it has been found that contact with nature can increase psychological well-being in children [30,31], emphasizing the greater benefits in rural environments compared with urban environments as well as the benefits for mental health in adolescents [32].

In this vein, connectedness to nature is a construct that is gaining importance in both the field of sustainability and health. For these reasons, researchers have tried to identify the variables that predict connectedness to nature. However, the results are controversial. Some research with children has focused on analyzing the role of experiences in natural environments and their relation to PEBs, finding positive relationships between them [33] and an increase in connectedness to nature [34]. Regarding age, connectedness to nature is related to PEBs in both adults $[12,27,28]$ and children [35]. Moreover, rural environments and the proximity of nature to home have been associated with greater connectedness to nature and the fostering of PEBs in children [36]. Conversely, other researchers have not found relationships between rural environments and well-being or sustainability [37]. Nonetheless, these same authors report relationships between health and sustainability in the domestic setting when activities in or visits to natural environments occur at least once a week. Other studies indicate that children aged 4-11 prefer urban environments to rural ones, even those living in contact with nature, and that this preference decreases as age increases [38].

To complete the picture, another indicator related to health, and, so, to well-being, is the cognitive component of well-being: satisfaction with life [39]. Studies have found positive relationships between satisfaction with life and connectedness to nature $[37,40]$. In adults, this relationship has been shown without significant differences for sex, ethnicity, or age [41], emphasizing that groups that tend to be more connected to nature tend to feel more satisfaction with life compared with those who are less connected to nature [38]. In this regard, it is stressed that environmental education for children should consider environmental sensitization and beliefs about the environment in order to promote SD [35].

Taking into account the reviewed literature, it seems that connectedness to nature is a key concept in the achievement and promotion of SD. Therefore, this study aims to identify the predictors of connectedness to nature in children and adolescents using knowledge of waste management and CE, PEBs, beliefs about caring for the environment, and satisfaction with life as possible predictive variables.

\section{Materials and Methods}

\subsection{Participants}

The non-probabilistic convenience sample consisted of 120 young people who were enrolled in state schools in rural areas of Castilla La Mancha (Spain). Of the participants, $97 \%$ were born in Spain. Twenty-three questionnaires were excluded for different reasons (seventeen because they were incorrectly completed and six because consent from the participant's family was not given). The final sample consisted of 97 young people (61.7\% boys). The sample's composition did not fit the national statistical proportion, which is close to a similar number of boys and girls. The average age of the participants was 14.24 years ( $\mathrm{SD}=2.71$ years) and ranged between 10 and 19 years. A total of $52.6 \%$ of the participants were under 12 years of age, which corresponds to Spanish Primary Education. 


\subsection{Measures}

Connectedness to nature. This was measured with the connectedness-to-nature scale (CNS) [40], whose authors found only one factor in the instrument. Similar findings were reported by Matas-Terrón and Elósegui-Bandera [42] with Spanish participants. Due to this fact, in this study, the one-factor structure was retained, and Matas-Terrón and Elósegui-Bandera's Spanish adaptation was used. This scale consists of 14 items that measure the feeling of being emotionally connected to the natural word (e.g., "I think of the natural world as a community to which I belong", "I often feel a kindship with animals and plants"). The level of agreement is indicated on a five-point Likert scale, from "totally disagree" (1) to "totally agree" (5), in order to respect the type of response offered by the authors of the tool [40]. The final score for connectedness to nature was taken to be the sum of the responses to all questions and items 4,12 , and 14 being reverse coded. It ranges from 14 to 70 , where higher scores are associated with a stronger feeling of being connected to the natural world. The CNS showed a high degree of internal consistency in our study (Cronbach's $\alpha=0.89$, which is higher than the value reported by Matas-Terrón and Elósegui-Barrera (2012) with Spanish participants (0.77) and similar to the one reported by Mayer and Franz [40] (0.84)).

Pro-environmental behavior. This was measured with the pro-environmental behaviors scale (PEBS) [43]. From this scale, the instrument was created through the selection and adaptation of items based on those behaviors that children and adolescents can perform autonomously on a daily basis. The answers were offered with a frequency scale that ranged from 1 (meaning "never") to 5 (meaning "always"). The items used were: "How often do you turn off the lights when leaving a room?", "How often do you switch off the standby mode of appliances or electronic devices?", "How often do you turn off the TV when leaving a room?", "How often do you limit your time in the shower in order to conserve water?", "How often do you separate out the different recyclable components of your garbage, such as glass, cans, plastics, or newspapers, for recycling?", "How often do you travel on foot or by bike?", "How often do you participate in actions in favor of the environment (cleaning beaches, cleaning parks, planting trees)?", "How frequently do you watch television programs, movies, or internet videos about environmental issues?", and "How often do you talk to others about their environmental behavior?". The final score was taken to be the sum of the responses to all questions and ranged from 9 to 45 , where higher scores indicate more pro-environmental behavior. The PEBS showed a high degree of internal consistency in our study (Cronbach's $\alpha=0.72$ ).

Satisfaction with life. The satisfaction with life scale (SWLS) [44] was used to measure this variable. This scale is widely used as a measure of judgments of subjective well-being and it consists of five items (e.g., "In most ways my life is close to my ideal" and "If I could live my life over, I would change almost nothing"). The level of agreement was indicated on a five-point Likert scale that ranged from "totally disagree" (1) to "totally agree" (5). The final score for satisfaction with life was taken to be the sum of the responses to all questions and ranged from 5 to 25, where higher scores indicate greater satisfaction with life. The SWLS showed a high degree of internal consistency in our study (Cronbach's $\alpha=0.84$ ).

Beliefs on environmental behavior (CIS) [45]. Seven items were chosen from the survey on the development of environmental behavior carried out by the Spanish Sociologic Research Center in 2010 [46]. Each item's wording was adapted to the vocabulary and comprehension structures of children. The answers were offered on a five-point Likert scale that ranged from "totally disagree" (1) to "totally agree" (5). The items were: "Young people like me can do things for the environment", "I do everything that is good for the environment, even if it costs me more money or takes me longer", "Protecting the environment is one of the most important things in life", "Even if others do not do the same, I personally have to do everything I can for the environment", "Statements about threats to the environment are based on research", "It is easy for me to know if my way of life is good or bad for the environment", and "Environmental problems have a direct effect on my daily life". This scale showed a high degree of internal consistency in our study (Cronbach's $\alpha=0.83$ ). 
Knowledge on circular economy. This questionnaire consists of 31 items that evaluate knowledge of key aspects of the circular economy on a scale that ranges from "nothing" (1) to "totally known" (5). Specifically, 21 items were developed ad hoc (e.g., "climate change", "ecosystem", and "sustainable development"), and 10 items were taken from Almeida et al. [47] (e.g., "I am aware of the repercussions of my way of life on the planet" and "The media encourages consumption"). The final score was taken to be the sum of the responses to all questions and ranged from 31 to 155, where higher scores indicate more knowledge of the $\mathrm{CE}$. The global scale showed a very high degree of internal consistency in our study (Cronbach's $\alpha=0.93$ ).

\subsection{Procedure}

The pilot study described in this paper is part of a wider project called "Creactive Science: Scientists in the Circular Economy", which is currently in force. The overall objective of the project is to raise awareness in society of the circular economy and women involved in research and the development of technology in this field. The data we present correspond to the evaluation performed prior to the project. Firstly, the project and the tests were presented to the teacher training center (the institution in charge of offering, coordinating, and providing training to teachers in the region). This institution informed the schools, and those who were interested signed up to participate in the project and informed families about both the project's aim and the evaluation. Finally, the participating students were informed that participation was voluntary and that they could freely withdraw by a family or an individual decision. A form was prepared with the described instruments using Google Forms, and demographic information was collected. To guarantee that students would understand the instruments, a comprehensive trial was carried out with 12 of the youngest students, and the wording of each item was adapted when needed. The study was conducted in compliance with the Declaration of Helsinki.

\subsection{Data Analysis}

Data were analyzed using IBM's Statistical Package for Social Sciences (SPSS) v24. First, an internal consistency analysis was performed using Cronbach's alpha in order to verify the reliability of each instrument. To check the data's normality, the Kolmogorov-Smirnov test was performed and $p$ values less than 0.05 were obtained for all of the variables. As a result, non-parametric statistics were applied. Therefore, the correlation of the variables was obtained using Spearman's Rho coefficient. The variables' connectedness to nature, pro-environmental behavior, satisfaction with life, beliefs about environmental behavior, and knowledge on circular economy were then categorized by taking into account the median as a cut-off point. Finally, a binary logistic regression was performed with connectedness to nature as a dependent variable in order to identify the predictors of it among the studied variables and the covariates (sex and age). The results are expressed with the odds ratio (OR) and the $95 \%$ confidence interval for each predictor. The Hosmer-Lemeshow test was undertaken to model goodness-of-fit.

\section{Results}

Table 1 presents the descriptive statistics for the demographics and all study variables according to the degree of connectedness to nature, and Table 2 shows the categorized variables according to the dependent variable levels. 
Table 1. Demographics of the participants and study variables.

\begin{tabular}{|c|c|c|c|c|c|c|c|c|}
\hline & \multicolumn{8}{|c|}{ Degree of Connectedness to Nature } \\
\hline & \multicolumn{4}{|c|}{ Low $(N=51)$} & \multicolumn{4}{|c|}{ High $(N=46)$} \\
\hline & Mean & SD & Min-Max & Range & Mean & SD & Min-Max & Range \\
\hline Age (years) & 14.04 & 2.77 & 10-19 & $10-19$ & 14.46 & 2.66 & $11-19$ & $10-19$ \\
\hline Sex (M:F) & $33: 16$ & & & & $25: 20$ & & & \\
\hline Pro-environmental behavior & 29.47 & 5.03 & $18-40$ & $9-45$ & 33.91 & 5.19 & $20-45$ & $9-45$ \\
\hline Satisfaction with life & 15.53 & 4.24 & $5-23$ & $5-25$ & 19.96 & 3.27 & $12-25$ & $5-25$ \\
\hline Beliefs about environmental behavior & 23.43 & 5.27 & $10-32$ & $7-35$ & 29.22 & 3.22 & $22-35$ & $7-35$ \\
\hline Knowledge on circular economy & 91.29 & 19.47 & $31-127$ & $31-155$ & 111.50 & 14.59 & $91-153$ & $31-155$ \\
\hline Connectedness to nature & 39.09 & 6.6 & $18-46$ & 28 & 55.73 & 6.16 & $47-69$ & 22 \\
\hline
\end{tabular}


Table 2. Mean (M) and standard deviation (SD) of categorized variables using the median as a cut-off point.

\begin{tabular}{lcccc}
\hline & \multicolumn{2}{c}{ Low Level } & \multicolumn{2}{c}{ High Level } \\
\cline { 2 - 5 } & M & SD & M & SD \\
\hline Age (years) & 11.98 & .85 & 17.07 & 1.14 \\
Pro-environmental behavior & 27.40 & 3.49 & 36.40 & 2.94 \\
Satisfaction with life & 14.68 & 3.37 & 21.32 & 2.15 \\
Beliefs about environmental behavior & 22.22 & 4.24 & 30.20 & 2.32 \\
Knowledge on circular economy & 86.85 & 15.84 & 115.18 & 12.11 \\
Connectedness to nature & 39.09 & 6.60 & 55.70 & 6.16 \\
\hline
\end{tabular}

Spearman's correlation coefficients for connectedness to nature are presented in Table 3. The results show that higher scores on connectedness to nature are related to higher scores on pro-environmental behaviors, satisfaction with life, beliefs about the environmental behaviors, and knowledge on circular economy (all $p<0.001$ ). Thus, in the high degree of connectedness-to-nature category, most of the analyzed predictors also exhibit a higher mean value. Therefore, a positive relationship can be inferred.

Table 3. Spearman's correlations between connectedness to nature and other variables of interest.

\begin{tabular}{lcccccc}
\hline & $\underline{\mathbf{1}}$ & $\underline{\mathbf{2}}$ & $\underline{\mathbf{3}}$ & $\underline{\mathbf{4}}$ & $\underline{\mathbf{5}}$ & $\underline{\mathbf{6}}$ \\
\hline 1. Connectedness to nature & - & & & & & \\
2. Pro-environmental behavior & $0.397^{* *}$ & - & & & & \\
3. Satisfaction with life & $0.590^{* *}$ & 0.196 & - & & & \\
4. Beliefs about environmental behavior & $0.695^{* *}$ & $0.295^{* *}$ & $0.445^{* *}$ & - & & \\
5. Knowledge on circular economy & $0.619^{* *}$ & $0.387^{* *}$ & $0.296^{* *}$ & $0.488^{* *}$ & - \\
6. Age & 0.090 & -0.072 & 0.174 & $0.246^{*}$ & -0.017 & - \\
\hline
\end{tabular}

Note: ${ }^{*}<0.05$ (bilateral); ${ }^{* *}<0.001$ (bilateral).

For our main exploration, we conducted a binomial logistic regression analysis with connectedness to nature as our categorical outcome and the high-level group as our contrast group. The differences between connectedness to nature and the high-low groups, obtained with the non-parametric Mann-Whitney test, were significant $(\mathrm{U}=2.34, p=0.000)$. The rest of the variables (i.e., pro-environmental behavior, satisfaction with life, beliefs about environmental behavior, and knowledge on circular economy) were included as predictors with the high-level group as the reference. Table 4 presents the results of the analysis, including the ORs and the $95 \%$ confidence interval for each predictor. ORs reflect the increase (or decrease) in the odds of a participant being in the contrast group relative to the high level of connectedness-to-nature group based on the change among categories for each predictor. For the predictors, the high degree of connectedness-to-nature category was taken as the reference.

Table 4. Binomial logistic regression based on the high level of connectedness-to-nature group as the reference group.

\begin{tabular}{lccc}
\hline & \multicolumn{3}{c}{ High vs. Low Connectedness to Nature } \\
\cline { 2 - 4 } & OR & $\mathbf{9 5 \%}$ CI & $p$ \\
\hline Pro-environmental behavior & $6.313^{*}$ & $1.725-23.106$ & 0.005 \\
Satisfaction with life & $7.018^{*}$ & $1.163-25.084$ & 0.003 \\
Beliefs about environmental behavior & $7.568^{*}$ & $2.028-28.242$ & 0.003 \\
Knowledge on circular economy & $9.077^{*}$ & $2.483-33.180$ & 0.001 \\
Age & 1.429 & $0.420-4.865$ & 0.568 \\
Sex & 1.097 & $0.327-3.687$ & 0.880 \\
\hline
\end{tabular}

Note: * Statistically significant relationship. 
The results reveal that there were significant differences between participants in the high vs. low degree of connectedness-to-nature group on pro-environmental behavior, satisfaction with life, beliefs about environmental behavior, and knowledge on circular economy. Specifically, compared with participants with a high level of pro-environmental behavior, the odds of being in the low degree of connectedness-to-nature group were higher in participants with a low level of pro-environmental behavior, low satisfaction with life, a low number of beliefs about environmental behavior, and little knowledge of circular economy ( $p=0.005, p=0.003, p=0.003$, and $p=0.001$, respectively). Finally, neither age nor sex were associated with a low or high degree of connectedness to nature (both $p>0.05$ ).

We will illustrate the interpretation of the OR for satisfaction with life via a comparison of the high degree of connectedness-to-nature group to the low degree of connectedness-to-nature group. The OR is 7.018 and represents the change in the odds of being in the low compared with being in the high degree of connectedness-to-nature group. In other words, a participant with low satisfaction with life is 7.018 times more likely to belong to the low degree of connectedness-to-nature group than a participant with high satisfaction with life.

The Nagelkerke coefficient shows that our model explained 60\% (maximum likelihood) of the total variance among groups in relation to the degree of connectedness to nature and demonstrated significant differences in the chi-squared distribution $\left(\chi^{2}=54.164, p<0.001\right)$. Moreover, our model accurately classified participants into the correct connectedness-to-nature group (see Table 5), with $80 \%$ of the participants correctly classified overall. Our model had a good fit when using the Hosmer-Lemeshow statistics $(p=0.787)$.

Table 5. Our model's classification performance.

\begin{tabular}{lccc}
\hline & \multicolumn{2}{c}{ Predicted } \\
\cline { 2 - 4 } & $\begin{array}{c}\text { Low Degree of } \\
\text { Connectedness to Nature }\end{array}$ & $\begin{array}{c}\text { High Degree of } \\
\text { Connectedness to Nature }\end{array}$ & $\begin{array}{c}\text { Percentage } \\
\text { Correct }\end{array}$ \\
\hline Low degree of connectedness to nature & 38 & 9 & $80.9 \%$ \\
High degree of connectedness to nature & 9 & 35 & $79.5 \%$ \\
Overall percentage & & & $80.2 \%$ \\
\hline
\end{tabular}

\section{Discussion}

This pilot study aimed to identify whether demographics, knowledge of CE, PEBs, beliefs about caring for the environment, and satisfaction with life are predictors of connectedness to nature in children and adolescents. For that purpose, we used a convenience sample of 97 Spanish students from rural schools.

Rural environments have not been widely analyzed in European countries. Nonetheless, in this respect the results are controversial. The positive relationships found in this study between PEBs, knowledge of $\mathrm{CE}$, beliefs about environmental behavior, satisfaction with life, and connectedness to nature in a rural environment support the recent study of Collado [33] and the previous ones of Cheng and Monroe [36] and Otto and Pensini [34], where correlations between sustainability, PEBs, and connectedness to nature in a rural environment were found. Our results also support studies in which an association between sustainability and experiences in natural environments was found, both in adults [30,31] and in children [32]. Conversely, our results contrast with those of Martina et al. [37], where no association between well-being and sustainability was found.

Regarding demographics, our data indicate that neither the age nor the sex of the participants was a predictor of connectedness to nature, thus confirming the results of other authors who did not find significant differences in sex or age in the relationships between satisfaction with life and connectedness to nature [41]. These data are interesting because they suggest, at least in this pilot study with young people, that gender roles do not affect the prediction of connectedness to nature, and, therefore, it can be assumed that there are no stereotypes associated with gender in this area. This finding contrasts with those of Liu et al. [48], who found a closer relation to nature for women. 
In relation to age, we did not find any studies conducted with children and adolescents with which to compare the age effect. Perhaps, due to the maturation process itself, a hypothesis could be that age has greater predictive power in older adolescents. Nonetheless, our results indicate that age lacks predictive power. This finding suggests that it would be convenient to work on connectedness to nature from as early an age as possible, since the simple passage of time does not seem to favor or create a link between adolescents and nature, thus requiring reinforcement via educational measures in order to increase such connectivity [48].

Knowledge of CE was the most significant factor in the studied sample, with an OR of 9, followed by beliefs about the environment, with an OR of 7.6. Our interpretation of the OR for knowledge is that the members of the group with the highest scores on knowledge are 9 times more likely to feel a higher degree of connectivity to nature than the members of the group with the lowest scores. These results emphasize the important role of education involving CE in the promotion of sustainable behaviors and pro-sustainable citizenship among children and adolescents to foster well-being, as reflected in the objectives of the 2030 Agenda [7] and reported by Rajapaksa et al. [20]. The requisite balance between knowledge and the social pillars of CE can be achieved through education $[5,48]$, which also contributes to the development of responsible citizenship in children and adolescents with suitable and internalized knowledge and beliefs related to CE [19,21].

Regarding satisfaction with life, we found that the members of the group with the highest scores were 7 times more likely to feel a higher degree of connectivity with nature. Considering that satisfaction with life is an indicator of well-being and, therefore, of health, this finding supports the positive and significant relationships between well-being, health, and connectivity with nature found in both adults [37,40,49] and children [35], although, in contrast with Wang and Kang's findings [16], it is only a reciprocal influence. In this vein, the results indicate that well-being is a relevant aspect to be considered in both public health agendas [50] and the United Nations SD agenda, i.e., the 2030 Agenda. It seems that human health is perceived by participants in a global sense and fully related to the health of the planet. For that reason, given the importance of connectivity with nature in children and adolescents, the educational system, social policies, and society in general must promote not only the internalization of beliefs and knowledge but also satisfaction with life.

In relation to beliefs about environmental behavior, the results obtained with this sample are positive and align with those presented in the general Spanish report [45]. Our analysis introduces the avenue of the connection of beliefs and connectedness to nature that was missing in the literature. Regarding pro-environmental behavior, the selected items refer to the choice of transportation, savings in supply and waste management, and involvement in activities that benefit the environment, thus following the definitions of PEBs provided by different authors [9-11] and included in the CE approach. This conceptualization of PEBs refers to behaviors that promote not only SD but also health, since the relationships found between PEBs and satisfaction with life involve a global perspective as outlined in the literature [13-15]. On the other hand, our results highlight the predictive capacity of PEBs, as an OR of 6.3 was obtained in relation to connectedness to nature. This finding coincides with research on adults that indicates a positive relationship between both variables [27], emphasizing the association between aspects of CE, i.e., recycling and waste management behavior [12], as well as participation in group activities that benefit the environment [28].

\section{Conclusions}

This pilot study produced two main findings. Firstly, we found relationships between knowledge of SD and CE, beliefs about caring for the environment, PEBs, satisfaction with life, and connectedness to nature. Secondly, we determined the predictive capacity of these variables in explaining connectivity with nature in a sample of children and adolescents from rural environments. All of the studied variables showed a high capacity for predicting the degree of connectedness to nature.

The relationships among the studied variables will be taken into account to establish a program of awareness and implement strategies related to the circular economy in educational and family 
settings, aimed primarily at children and adolescents and their educational and family environment. In addition, future studies will seek to obtain more psychometric data on the instruments used, study the possible theoretical models of the relationship between variables, and check the effectiveness of the implemented programs.

However, there are several limitations to our study that should be taken into account before generalizing the results. One limitation is the sample size, which has been indicated to be a limitation by authors in studies with a similar sample size [51,52], sample composition, and age range. Moreover, the lack of control over strange variables, such as socio-economic data on families, limits the generalizability of our results.

As a future line of research, it would be interesting to carry out longitudinal studies to verify whether the relationships found in childhood and adolescence are maintained or evolve in adulthood. Moreover, a larger sample is needed in order to explore by advanced estimation methods, such as the structural equations model, the relations among these variables. It would also be interesting to add other psychosocial variables in order to determine which ones have direct effects and which variables act as modulators in the possible predictive models. Additionally, it would be useful to consider all of this information when designing educational programs that could promote active methodologies involving $\mathrm{CE}$, and to check, on the one hand, whether they improve the degree of connectedness to nature in childhood and adolescence and, on the other, if they promote short-term behaviors in citizens that guarantee sustainable development and well-being, which are important aspects of the survival of the planet and human beings.

Author Contributions: Conceptualization, R.F.-C., D.G., F.G.-B., and N.S.-P.; methodology, R.F.-C., D.G., and N.S.-P.; formal analysis, R.F.-C., D.G., F.G.-B., and N.S.-P.; investigation, R.F.-C., D.G., F.G.-B., and N.S.-P.; writing - original draft preparation, R.F.-C., D.G., F.G.-B., and N.S.-P.; writing-review and editing, R.F.-C., D.G., F.G.-B., and N.S.-P.; project administration, R.F.-C. and N.S.-P.; funding acquisition, R.F.-C. and N.S.-P. All authors have read and agreed to the published version of the manuscript.

Funding: This research was funded by the Spanish Foundation for Science and Technology (grant number FCT-18-13150) and Castilla La Mancha University co-funded by the European Fund for Regional Development (grant number 2020-GRIN-29110).

Acknowledgments: We acknowledge the Regional Center for Teacher Training of Castilla la Mancha, Spain, and the researchers and primary and secondary education schools participating in the project Creactive Science: Scientists in the Circular Economy, available at https://cienciacreactiva.bio3project.es/.

Conflicts of Interest: The authors declare no conflict of interest.

\section{References}

1. Robert, K.W.; Parris, T.M.; Leiserowitz, A.A. What is Sustainable Development? Goals, Indicators, Values, and Practice. Environ. Sci. Policy Sustain. Dev. 2005, 47, 8-21. [CrossRef]

2. Prieto-Sandoval, V.; Jaca, C.; Ormazabal, M. Economía circular: Relación con la evolución del concepto de sostenibilidad y estrategias para su implementación. Mem. Investig. Ing. 2017, 15, 85-95.

3. Sánchez-Emeterio, G.; Figueira, C. Eco-social Literacy: Circular Economy Conceptions in Initial Teacher Training. In Proceedings of the 9th International Conference the Future of Education, Florence, Italy, 27-28 June 2019; pp. 486-490.

4. Liu, Z.; Adams, M.; Cote, R.P.; Geng, Y.; Li, Y. Comparative study on the pathways of industrial parks towards sustainable development between China and Canada. Resour. Conserv. Recycl. 2018, 128, 417-425. [CrossRef]

5. Nikanorova, M.; Stankevičienè, J. Development of environmental pillar in the context of circular economy assessment: Baltic Sea Region case. Entrep. Sustain. Issues 2020, 8, 1209-1223. [CrossRef]

6. Kirchherr, J.; Reike, D.; Hekkert, M. Conceptualizing the circular economy: An analysis of 114 definitions. Resour. Conserv. Recycl. 2017, 127, 221-232. [CrossRef]

7. Schroeder, P.; Anggraeni, K.; Weber, U. The Relevance of Circular Economy Practices to the Sustainable Development Goals. J. Ind. Ecol. 2018, 23, 7795. [CrossRef] 
8. Sustainable Development Goals-SDGs—The United Nations. Available online: https://sdgs.un.org/goals (accessed on 20 January 2020).

9. Wynes, S.; Nicholas, K.A. The climate mitigation gap: Education and government recommendations miss the most effective individual actions. Environ. Res. Lett. 2017, 12, 074024. [CrossRef]

10. She, Z.; King, D.M.; Jacobson, S.H. Analyzing the impact of public transit usage on obesity. Prev. Med. 2017, 99, 264-268. [CrossRef]

11. Wyles, K.J.; Pahl, S.; Holland, M.; Thompson, R.C. Can Beach Cleans Do More Than Clean-Up Litter? Comparing Beach Cleans to Other Coastal Activities. Environ. Behav. 2017, 849, 509-535. [CrossRef]

12. Gkargkavouzi, A.; Halkos, G.; Matsiori, S. A Multi-dimensional Measure of Environmental Behavior: Exploring the Predictive Power of Connectedness to Nature, Ecological Worldview and Environmental Concern. Soc. Indic. Res. 2019, 143, 859-879. [CrossRef]

13. Rosa, C.D.; Collado, S. Enhancing Nature Conservation and Health: Changing the Focus to Active Pro-environmental Behaviours. Psychol. Stud. 2019, 65, 9-15. [CrossRef]

14. Evans, G.W. Projected Behavioral Impacts of Global Climate Change. Annu. Rev. Psychol. 2019, 70, 449-474. [CrossRef] [PubMed]

15. Kaida, N.; Kaida, K. Positive associations of optimism-pessimism orientation with pro-environmental behavior and subjective well-being: A longitudinal study on quality of life and everyday behavior. Qual. Life Res. 2019, 28, 3323-3332. [CrossRef] [PubMed]

16. Wang, E.; Kang, N. Does life satisfaction matter for pro-environmental behavior? Empirical evidence from China General Social Survey. Qual. Quant. 2019, 53, 449-469. [CrossRef]

17. Li, D.; Zhao, L.; Ma, S.; Shao, S.; Zhang, L. What influences an individual's pro-environmental behavior? A literature review. Resour. Conserv. Recycl. 2019, 146, 28-34. [CrossRef]

18. Buil, P.; Roger-Loppacher, O.; Selvam, R.M.; Prieto-Sandoval, V. The Involvement of Future Generations in the Circular Economy Paradigm: An Empirical Analysis on Aluminium Packaging Recycling in Spain. Sustainability 2017, 9, 2345. [CrossRef]

19. Nadlifatin, R.; Lin, S.-C.; Rachmaniati, Y.P.; Persada, S.F.; Razif, M. A Pro-Environmental Reasoned Action Model for Measuring Citizens' Intentions regarding Ecolabel Product Usage. Sustainability 2016, 8, 1165. [CrossRef]

20. Rajapaksa, D.; Islam, M.; Managi, S. Pro-Environmental Behavior: The Role of Public Perception in Infrastructure and the Social Factors for Sustainable Development. Sustainability 2018, 10, 937. [CrossRef]

21. Guo, P.; Zhang, X. Study on Circular Economy Education in Rural Areas in China. In Proceedings of the International Conference on Logistics, Engineering, Management and Computer Science, Shenyang, China, 24-26 May 2014.

22. Ley Orgánica 8/2013, de 9 de Diciembre, para la Mejora de la Calidad Educativa (LOMCE). Boletín Oficial del Estado, España, 295. Available online: http://www.boe.es/boe/dias/2013/12/10/pdfs/BOE-A-2013-12886.pdf (accessed on 10 September 2020).

23. Schultz, P.W. Inclusion with Nature: The Psychology OF Human-Nature Relations. In Psychology of Sustainable Development; Schmuck, P., Schultz, P.W., Eds.; Kluwer Academic Publishers: Dordrecht, The Netherlands, 2002; pp. 61-78.

24. Clayton, S.; Opotow, S. Identity and the Natural Environment: The Psychological Significance of Nature; MIT Press: Cambridge, MA, USA, 2003.

25. Clayton, S.D. Environment and Identity. In Handbook of Environmental and Conservation Psychology; Clayton, S., Ed.; Oxford University Press: New York, NY, US, 2012; pp. 164-180.

26. Crompton, T.; Kasser, T. Human Identity: A Missing Link in Environmental Campaigning. Environ. Sci. Policy Sustain. Dev. 2010, 52, 23-33. [CrossRef]

27. Tam, K.-P. Concepts and measures related to connection to nature: Similarities and differences. J. Environ. Psychol. 2013, 34, 64-78. [CrossRef]

28. Whitburn, J.; Linklater, W.L.; Milfont, T.L. Exposure to Urban Nature and Tree Planting Are Related to Pro-Environmental Behavior via Connection to Nature, the Use of Nature for Psychological Restoration, and Environmental Attitudes. Environ. Behav. 2019, 51,787-810. [CrossRef]

29. Wyles, K.J.; White, M.; Hattam, C.; Pahl, S.; King, H.; Austen, M. Are Some Natural Environments More Psychologically Beneficial Than Others? The Importance of Type and Quality on Connectedness to Nature and Psychological Restoration. Environ. Behav. 2019, 51, 111-143. [CrossRef] 
30. Wells, N.M.; Evans, G.W. Nearby Nature. Environ. Behav. 2003, 35, 311-330. [CrossRef]

31. Sobko, T.; Jia, Z.; Brown, G. Measuring connectedness to nature in preschool children in an urban setting and its relation to psychological functioning. PLoS ONE 2018, 13, e0207057. [CrossRef] [PubMed]

32. Piccininni, C.; Michaelson, V.; Janssen, I.; Pickett, W. Outdoor play and nature connectedness as potential correlates of internalized mental health symptoms among Canadian adolescents. Prev. Med. 2018, 112, 168-175. [CrossRef]

33. Collado, S.; Evans, G.W. Outcome expectancy: A key factor to understanding childhood exposure to nature and children's pro-environmental behavior. J. Environ. Psychol. 2019, 61, 30-36. [CrossRef]

34. Otto, S.; Pensini, P. Nature-based environmental education of children: Environmental knowledge and connectedness to nature, together, are related to ecological behaviour. Glob. Environ. Chang. 2017, 47, 88-94. [CrossRef]

35. Wu, L.; Lingqiong, W. The relationships between environmental sensitivity, ecological worldview, personal norms and pro-environmental behaviors in Chinese children: Testing the value-belief-norm model with environmental sensitivity as an emotional basis. PsyCh J. 2018, 7, 111-121. [CrossRef]

36. Cheng, J.C.-H.; Monroe, M.C. Connection to Nature. Environ. Behav. 2012, 44, 31-49. [CrossRef]

37. Martin, L.; White, M.P.; Hunt, A.; Richardson, M.; Pahl, S.; Burt, J. Nature contact, nature connectedness and associations with health, wellbeing and pro-environmental behaviours. J. Environ. Psychol. 2020, 68, 101389. [CrossRef]

38. Meidenbauer, K.L.; Stenfors, C.U.; Young, J.; Layden, E.A.; Schertz, K.E.; Kardan, O.; Decety, J.; Berman, M.G. The gradual development of the preference for natural environments. J. Environ. Psychol. 2019, 65, 101328. [CrossRef]

39. Diener, E.; Lucas, R.; Oishi, S. Subjetive well-being: The science of happiness and life satisfaction. In Handbook of Positive Psychology; Snyder, C., López, S., Eds.; Oxford University Press: New York, NY, USA, 2002; pp. 63-73.

40. Mayer, F.; Frantz, C.M. The connectedness to nature scale: A measure of individuals' feeling in community with nature. J. Environ. Psychol. 2004, 24, 503-515. [CrossRef]

41. Zhang, J.W.; Howell, R.T.; Iyer, R. Engagement with natural beauty moderates the positive relation between connectedness with nature and psychological well-being. J. Environ. Psychol. 2014, 38, 55-63. [CrossRef]

42. Matas-Terrón, A.; Elósegui-Bandera, E. Características psicométricas de la Escala de Conectividad con la Naturaleza en una muestra universitaria. Psyecology 2012, 3, 41-51. [CrossRef]

43. Markle, G.L. Pro-Environmental Behavior: Does It Matter How It's Measured? Development and Validation of the Pro-Environmental Behavior Scale (PEBS). Hum. Ecol. 2013, 41, 905-914. [CrossRef]

44. Diener, E.; Emmons, R.A.; Larsen, R.J.; Griffin, S. The Satisfaction with Life Scale. J. Pers. Assess. 1985, 49, 71-75. [CrossRef]

45. Centro de Investigaciones Sociológicas. Estudio 2837, España. Available online: http://www.cis.es/cis/ opencm/ES/1_encuestas/estudios/ver.jsp?estudio=11404 (accessed on 10 March 2020).

46. Desarrollo del comportamiento proambiental en los individuos y sus determinantes/Development of Pro-Environmental Conduct in Individuals and its Determinants. Revista Española de Investig. Sociológicas 2018, 163, 59-78. [CrossRef]

47. Almeida, A.; Fernández, B.G.; Emeterio, G.S. Assessment of pre-service teachers' knowledge of the impact of livestock production on global warming: A comparative study between Portugal and Spain. Int. J. Environ. Stud. 2016, 73, 939-953. [CrossRef]

48. Liu, T.; Geng, L.; Ye, L.; Zhou, K. "Mother Nature" enhances connectedness to nature and pro-environmental behavior. J. Environ. Psychol. 2019, 61,37-45. [CrossRef]

49. Capaldi, C.A.; Dopko, R.L.; Zelenski, J.M. The relationship between nature connectedness and happiness: A meta-analysis. Front. Psychol. 2014, 5, 976. [CrossRef]

50. World Health Organization. The European Health Report 2012: Charting the Way to Well-Being; WHO: Copenhague, Denmark, 2013.

51. Han, G.; Martin, R.A. Teaching and Learning about Biomass Energy: The Significance of Biomass Education in Schools. Sustainability 2018, 10, 996. [CrossRef] 
52. Cerezo, R.; Esteban, M.; Vallejo, G.; Sanchez-Santillan, M.; Nuñez, J.C. Differential Efficacy of an Intelligent Tutoring System for University Students: A Case Study with Learning Disabilities. Sustainability 2020, 12, 9184. [CrossRef]

Publisher's Note: MDPI stays neutral with regard to jurisdictional claims in published maps and institutional affiliations.

(C) 2020 by the authors. Licensee MDPI, Basel, Switzerland. This article is an open access article distributed under the terms and conditions of the Creative Commons Attribution (CC BY) license (http://creativecommons.org/licenses/by/4.0/). 